\title{
Recent Advances in Energy Time Series Forecasting
}

\author{
Francisco Martínez-Álvarez ${ }^{1, *}$, Alicia Troncoso ${ }^{1}$ and José C. Riquelme ${ }^{2}$ \\ 1 Department of Computer Science, Pablo de Olavide University, ES-41013 Seville, Spain; atrolor@upo.es \\ 2 Department of Computer Science, University of Seville, 41012 Seville, Spain; riquelme@us.es \\ * Correspondence: fmaralv@upo.es; Tel.: +34-954-977-730 \\ Academic Editor: Enrico Sciubba \\ Received: 8 June 2017; Accepted: 12 June 2017; Published: 14 June 2017
}

\begin{abstract}
This editorial summarizes the performance of the special issue entitled Energy Time Series Forecasting, which was published in MDPI's Energies journal. The special issue took place in 2016 and accepted a total of 21 papers from twelve different countries. Electrical, solar, or wind energy forecasting were the most analyzed topics, introducing brand new methods with very sound results.
\end{abstract}

Keywords: energy; time series; forecasting

This special issue has focused on the forecasting of time series, with particular emphasis on energy-related data. By energy, it was understood to mean any kind of energy, such as electrical, solar, or wind.

Authors were invited to submit their original research and review articles exploring the issues and applications of energy time series and forecasting.

Topics of primary interest included, but were not limited to:

(1) Energy-related time series analysis.

(2) Energy-related time series model.

(3) Energy-related time series forecasting.

(4) Non-parametric time series approaches.

From all the submissions received, only those with very high quality scientific content and innovativeness were accepted, after rigorous peer review. A total of twenty-one papers were accepted, with the following author's geographical distribution:

(1) China (9).

(2) Spain (4).

(3) Sweden (1).

(4) Australia (1).

(5) Italy (1).

(6) Austria (1).

(7) Belgium (1).

(8) UK (1).

(9) Korea (1).

(10) United Arab Emirates (1).

(11) Saudi Arabia (1).

(12) Turkey (1).

The submissions received can be broadly divided into the following topics. First, electricity demand forecasting has been addressed by using deep neural networks [1], cointegration techniques [2], random forests [3], imbalanced classification for outlying data [4], or non-linear autoregressive neural networks [5]. Another hot topic - that is, electricity price forecasting-has also been analyzed in this special issue by means of an empirical mode decomposition-based multiscale methodology [6] or by 
averaging dynamic factor models [7]. Finally, a comparative study of hybrid models based on a series of optimization algorithms in the electricity context can be found in [8].

Two key aspects in wind energy have been studied in this special issue: wind speed and wind power generation. On the one hand, an ensemble system with weather-adapted correction [9] and a method combining metaheuristics, spectrum analysis, and neural networks [10] have been proposed for wind speed forecasting. On the other hand, wind power generation forecasting has been analyzed by applying hybrid approaches [11,12], and with a method exhibiting physical coupling to the weather [13].

Two interesting manuscripts have been published in the field of solar energy generation. Thus, an ensemble learning approach for probabilistic forecasting can be found in [14] and a neural network ensemble for solar photovoltaic power 2-D interval forecasting in [15].

City natural gas and coal price have also been forecasted. In particular, the authors in [16] discussed and wondered if the steam coal price will rebound under the new economy normalcy in China. By contrast, one-year-ahead demand forecast of city natural gas using seasonal time series methods was introduced in [17].

Finally, other relevant topics, such as forecasting the state of health of electric vehicle batteries [18], a time series clustering based battery grouping method [19], financing innovations for the renewable energy transition in Europe [20], or clustering energy markets [21] have been analyzed and discussed within this special issue.

Acknowledgments: Guest editors would like to express their sincerest gratitude to Energies' in-house editors and reviewers for their wonderful work and effort. Without their support, the efficient handling of all received manuscripts (article average processing time was 104 days), it would not have been possible to publish this special issue. The Spanish Ministry of Economy and Competitiveness is also acknowledged for the support under project TIN2014-55894-C2-R.

Conflicts of Interest: The authors declare no conflict of interest.

\section{References}

1. Ryu, S.; Noh, J.; Kim, H. Deep Neural Network Based Demand Side Short Term Load Forecasting. Energies 2017, 10, 3 .

2. Hasanov, F.J.; Hunt, L.C.; Mikayilov, C.I. Modeling and Forecasting Electricity Demand in Azerbaijan Using Cointegration Techniques. Energies 2016, 9, 1045.

3. Huang, N.; Lu, G.; Xu, D. A Permutation Importance-Based Feature Selection Method for Short-Term Electricity Load Forecasting Using Random Forest. Energies 2016, 9, 767.

4. Duque-Pintor, F.J; Fernández-Gómez, M.J.; Troncoso, A.; Martínez-Álvarez, F. A New Methodology Based on Imbalanced Classification for Predicting Outliers in Electricity Demand Time Series. Energies 2016, 9, 752.

5. Baca Ruiz, L.G.; Pegalajar Cuéllar, M.; Delgado Calvo-Flores, M.; Pegalajar Jiménez, M.C. An Application of Non-Linear Autoregressive Neural Networks to Predict Energy Consumption in Public Buildings. Energies 2016, 9, 684 .

6. He, K.; Wang, H.; Du, J.; Zou, Y. Forecasting Electricity Market Risk Using Empirical Mode Decomposition (EMD)—Based Multiscale Methodology. Energies 2016, 9, 931.

7. Alonso, A.M.; Bastos, G.; García-Martos, C. Electricity Price Forecasting by Averaging Dynamic Factor Models. Energies 2016, 9, 600.

8. Ma, X.; Liu, D. Comparative Study of Hybrid Models Based on a Series of Optimization Algorithms and Their Application in Energy System Forecasting. Energies 2016, 9, 640.

9. Chu, Y.; Li, C.; Wang, Y.; Li, J.; Li, J. A Long-Term Wind Speed Ensemble Forecasting System with Weather Adapted Correction. Energies 2016, 9, 894.

10. Gao, Y.; Qu, C.; Zhang, K. A Hybrid Method Based on Singular Spectrum Analysis, Firefly Algorithm, and BP Neural Network for Short-Term Wind Speed Forecasting. Energies 2016, 9, 757.

11. Wu, Q.; Peng, C. Wind Power Generation Forecasting Using Least Squares Support Vector Machine Combined with Ensemble Empirical Mode Decomposition, Principal Component Analysis and a Bat Algorithm. Energies 2016, 9, 261. 
12. Wu, Q.; Peng, C. A Least Squares Support Vector Machine Optimized by Cloud-Based Evolutionary Algorithm for Wind Power Generation Prediction. Energies 2016, 9, 585.

13. Olauson, J.; Bladh, J.; Lonnberg, J.; Bergkvist, M. A New Approach to Obtain Synthetic Wind Power Forecasts for Integration Studies. Energies 2016, 9, 800.

14. Ahmed Mohammed, A.; Aung, Z. Ensemble Learning Approach for Probabilistic Forecasting of Solar Power Generation. Energies 2016, 9, 1017.

15. Rana, M.; Koprinska, I. Neural Network Ensemble Based Approach for 2D-Interval Prediction of Solar Photovoltaic Power. Energies 2016, 9, 829.

16. Guo, X.; Wei, Y.; Yuan, J. Will the Steam Coal Price Rebound under the New Economy Normalcy in China? Energies 2016, 9, 751 .

17. Akpinar, M.; Yumusak, N. Year Ahead Demand Forecast of City Natural Gas Using Seasonal Time Series Methods. Energies 2016, 9, 727.

18. Semanjski, I.; Gautama, S. Forecasting the State of Health of Electric Vehicle Batteries to Evaluate the Viability of Car Sharing Practices. Energies 2016, 9, 1025.

19. He, Z.; Gao, M.; Ma, G.; Liu, Y.; Tang, L. Battery Grouping with Time Series Clustering Based on Affinity Propagation. Energies 2016, 9, 561.

20. Bointner, R.; Pezzutto, S.; Grilli, G.; Sparber, W. Financing Innovations for the Renewable Energy Transition in Europe. Energies 2016, 9, 990.

21. Ruiz-Abellán, M.C.; Gabaldón, A.; Guillamón, A. Dependency-Aware Clustering of Time Series and Its Application on Energy Markets. Energies 2016, 9, 809.

(C) 2017 by the authors. Licensee MDPI, Basel, Switzerland. This article is an open access article distributed under the terms and conditions of the Creative Commons Attribution (CC BY) license (http:/ / creativecommons.org/licenses/by/4.0/). 